\title{
Proyecto Memória Votorantin (PMV): un centro de documentación en línea
}

\author{
Projeto Memória Votorantim (P.M.V.) (1): Um centro de documentação on line(2)
}

Votorantim Memory Project: a documentation centre on line

Derlei Alberto dos Santos (1), Telma Campanha de Carvalho Madio (2)

Universidade Estadual Paulista Júlio de Mesquita Filho, UNESP, Departamento de Ciência da Informação, Av. Hygino Muzzi Filho, 737, Campus Universitário, CEP. 17525-900, Marília, SP, Brasil, Caixa-Postal: 421. (1) derlei@assis.unesp.br (2) telmaccarvalho@marilia.unesp.br

\begin{abstract}
Resumen
Esta investigación se centra en la formación y consolidación del Proyecto Memoria Votorantim (PMV), presentado al gran publico en 2005 , con la publicación de su sitio en la Web. El eje central fundamental es comprender su "arquitectura" y los contenidos específicos de sus distintas secciones, identificando los conjuntos informativos y los repertorios documentales que lo integran, buscando entender los propósitos de su constitución. Se busca discutir la constitución del PMV como parte de las estrategias del crecimiento de los negocios de la Votorantim anunciados en 2004, edificando la tradición del Grupo Votorantim y actuando como refuerzo y ampliación de la corporativa de sus empleados.
\end{abstract}

Palabras clave: Centros de documentación. Archivos. Archivos institucionales. Internet. Grupo Votorantim.

\section{Introdução}

É importante considerar que o Grupo Votorantim está a menos de uma década de seu centenário, que ocorrerá em 2018. Durante 80 anos de sua história essa corporação não expressou uma preocupação relevante com sua memória e seu significado institucional. A exceção foi a publicação das biografias de seus fundadores (1974 e 1975). Definiu-se, como núcleo de memória, a tríade de empresários que comandaram e protagonizaram a trajetória do Grupo: o fundador, Comendador Pereira Ignácio (pai), o visionário Senador José Ermírio de Moraes (genro) e o inovador Antônio Ermírio de Moraes (neto). Uma aparente mitificação dos seus feitos estabeleceu-se como elo unificador das ações corporativas.

No entanto, com a crescente diversificação dos negócios do Grupo Votorantim, ele passou a se fazer presente em quase todos os estados brasileiros e nos cinco continentes. Então, esse elo de identidade, estabelecido nas relações de trabalho restritas à cidade de Votorantim e, pos-

\begin{abstract}
The origins and consolidation of the Votorantim Memory Project are discussed. The project was presented to the public in 2005, with the publication of its web site. Its architecture and the specific contents of each section are presented, identifying its informative sets and its document repositories. The working hypothesis is that the official history of the Votorantim Group is the result of the confluence between the workers' memories and the corporate recollection. The background of the project is discussed in the frame of the growth strategy of the company, announced in 2004, and its corporate culture. The project contributes to the reinforcement and amplification of the employees' corporate affiliation.
\end{abstract}

Keywords: Documentation centre. Collections. Archives. Institutional archives. Internet. Votorantim Corporation.

teriormente, estendido a algumas outras cidades do Estado de São Paulo, necessitou de uma reformulação. A intenção desta pesquisa, também, é verificar como o Proyecto Memória Votorantim (PMV) (1). assumiu essa função, por meio da construção, consolidação e propagação da memória corporativa, tornando-a o eixo condutor de uma narrativa local, com pontos de conexão com a história nacional.

A pesquisa tem como foco os arquivos públicos e privados, particulares e institucionais, das cidades de Votorantim e Sorocaba, com o intuito de verificar, no exame de seus conteúdos e tipologias, a existência de indicadores de uma mitificação da biografia da Família Ermírio de Moraes, proprietária do Grupo das empresas Votorantim instaladas na região.

Temos os seguintes objetivos: compreender o papel e a função dos arquivos na construção da memória local e nacional; verificar a relação entre arquivos e construções biográficas de várias modalidades; e, por fim, identificar e descrever as tipologias documentais encontradas no Projeto Memória Votorantim. que tiveram 
outros fundos de origem e foram "apropriados" no arquivo institucional formando o que consideramos um novo fundo. Esses arquivos foram recolhidos dos arquivos pessoais da população local que foram guardados através dos anos pelas famílias que moraram em Votorantim e que sofreram o impacto da fundação e do crescimento das indústrias do Grupo.

Algumas indagações presidiram o desenvolvimento do trabalho de iniciação científica: fazer um levantamento dos arquivos locais, identificando suas linhas de formação de acervo. O que permitiria descobrir os fatores que, então, teriam sido considerados para a construção de uma memória, de um passado comum? Como a formação desses arquivos poderia contribuir para o melhor entendimento da construção de uma história local sob óticas diferentes? Como, na esfera pública, os seus arquivos formam a base da memória local? Como se constrói, na esfera institucional privada - no caso, dos arquivos do Grupo Votorantim - a memória do conglomerado industrial através de determinados conjuntos documentais de seus arquivos, que ficam disponíveis para os próprios funcionários? Qual o valor simbólico que atribuem a esses documentos? Como são utilizados para invocar as lembranças de um passado pessoal e coletivo?

Durante a realização do projeto de iniciação científica pude constatar indícios de uma forte construção mítica presente nos tipos de documentos que integravam os arquivos pessoais e os das instituições locais, públicos e privados. Foi durante esse levantamento que me deparei com a construção de algo maior, a formação do PMV e sua exposição midiática através do site www.memoriavotorantim.com.br. Nele, esse imbricamento da memória tomou proporções notáveis reunindo acervos fragmentados nas empresas espalhadas por todo país. São reunidos, catalogados e utilizados para contar a história do grupo Votorantim como capítulo importante da história nacional. Ressalte-se que a construção dessa história apresenta um processo simbiótico da história da empresa e da história da cidade, revelando-se como um espaço em que a memória é fortemente disputada através da posse dos arquivos referidos anteriormente. Esses questionamentos estão recebendo o devido aprofundamento agora na pesquisa da Pós-Graduação tendo como principal escopo a problemática da formação, consolidação e exposição do PMV.

Desse ângulo de abordagem será necessário apontar as circunstâncias e as conjunturas que levaram à formação do PMV e de sua referida abrangência. Como, em menos de dez anos, foi formado e mapeado um acervo que é composto de aproximadamente 80 mil documentos? Quais foram os critérios de seleção utilizados para montar a interface visual do site com os arquivos que nele são apresentados? Qual é a importância do site como ferramenta propagadora dessa memória? Como a memória corporativa foi sendo introduzida, como elemento focal, sobre a memória do trabalhador?

Para tanto será necessário proceder ao levantamento, identificação e análise da tipologia da documentação reunida pelo PMV., procurando, sempre que possível, identificar sua origem documental, visto que há indícios de construção de uma mitobiografia (2) da tríade de empresários, fortemente reforçada nos conteúdos documentais que integram os arquivos locais, institucionais e pessoais (3). Dessa forma poderemos compreender como se desenvolveu o processo que definiu os conjuntos documentais que estariam disponíveis a consultas na sua sede, na Praça Ramos de Azevedo (4) os que ficaram expostos para consulta no site, e como esses últimos foram utilizados para um entrelaçamento entre a história institucional do Grupo com a história do país.

É pressuposto deste trabalho que, no âmbito local, na gênese do Grupo Votorantim, instalado na cidade que leva o mesmo nome, teria havido a produção de uma memória, materializada em trabalhos publicados sobre a família Moraes e, principalmente, nos arquivos locais.

Assim constitui-se a hipótese de que os arquivos pessoais, oriundos principalmente dos trabalhadores daquelas empresas, aos poucos, por meio de doações ao PMV. ou de empréstimos para reprodução, tornaram-se institucionais e desempenharam as funções de comprovar e de perpetuar versões biográficas (de concepção exemplar) que impregnaram o imaginário local. Atualmente são utilizados para atingir uma projeção nacional, uma vez que a história pequena, ímpar, tanto da cidade quanto da empresa, só aparece agregada de valor se estiver ligada à história nacional, que teriam ajudado a construir.

O projeto possui um caráter interdisciplinar, situando-se entre a história e a arquivologia. É preciso descobrir e analisar os registros documentais que estão sendo considerados pelo PMV. como indicadores da realidade histórica formulada. Esses registros constituem os elementos fundamentais de sua construção. Não há dúvida que as imagens criadas para representar essa história continuam ancoradas nas ações do "núcleo duro" da memória, constituído pela tríade de empresários, responsáveis pelo êxito dos empreendimentos do grupo, pois en- 
volveram intensamente a comunidade e sua projeção nacional. Nesse sentido, teriam constituído fator decisivo para o desenvolvimento da cidade de Votorantim, do Estado de São Paulo e do Brasil. A cultura empresarial, portanto, mesclou-se com a cultura local no imaginário dos moradores e trabalhadores das comunidades onde havia ramificações do Grupo, operando principalmente como elemento neutralizador de diferenças e de conflitos sociais.

\section{A região de Sorocaba, a cidade de Votorantim e a gênese do Grupo Votorantim}

A região de Sorocaba, no Estado de São Paulo, tem características herdadas da rota tropeira, base do fortalecimento do comércio interno no Brasil (Vaintas, p. 565). Essa tradição de comércio e o fácil acesso à capital (cerca de 100 $\mathrm{km}$ ) constituíram terreno fértil para gerar as condições que levaram essa região, no final do século XIX, a integrar o processo de industrialização de São Paulo (Warren, 1971). As rotas abertas pelo interior paulista se transformaram nas vias férreas que tiveram em Sorocaba sua conexão principal, pela Estrada de Ferro Sorocabana.

Outros fatores podem ser mencionados para delinear as conjunturas que favoreceram a expansão da industrialização para essa região do interior paulista, como condições ambientais específicas: recursos minerais, presença da Mata Atlântica, clima ameno e um manancial fluvial favorável à extração de minerais e ao represamento para produção de energia elétrica foram decisivos para a industrialização. Somase o fato de que a história econômica da região, de intenso comércio, era também reduto de grandes fazendeiros. Alguns deles, em declínio, vendiam suas terras a baixo preço. Outros, ainda prósperos, continuavam com seus negócios ou se aventuravam para o capital industrial.

Outros fatores dignos de nota são: a inexatidão dos limites de terras, que atraía os investidores para o interior, e a mão-de-obra local, que era desqualificada em sua grande maioria e, portanto, barata, ainda imune às influências das organizações de trabalhadores dos centros maiores, trazendo novas vantagens e facilitando a instalação de inúmeras empresas na região de Sorocaba.

Alguns estudiosos locais (Almeida, 2002) apontam, como fator de desenvolvimento diferenciado na região, o seu passado tropeiro, que contribuiu para fortalecer o comércio. Desenvolvendo o perfil empreendedor do sorocabano somado às riquezas naturais provenientes dessa terra, fazendo com que os donos de capitais locais se aventurassem na industrialização. Os recursos naturais (5) atraíram industriais já consolidados do Brasil, bem como outros comerciantes que acumularam um pequeno capital procedente de suas atividades comerciais, que muitas vezes estavam situados nas cidades por onde passava a linha da Sorocabana. Portanto, tinham uma facilidade para saber o que ocorria em Sorocaba e assim sentiam-se seduzidos para investir no promissor ramo das indústrias. Pode-se apontar ao menos uma pessoa em especial, que seguiu esse pensamento. Após anos como viajante e sapateiro, estabeleceu um pequeno comércio de "Secos e Molhados" na cidade de Botucatu (passagem da Sorocabana), reunindo suas economias e comprando os ativos de uma falida fábrica têxtil na cidade de Sorocaba em 1917. Trata-se do imigrante e futuro Comendador, Pereira Inácio, patriarca e fundador das Indústrias Votorantim (6). O que contribuiu para que futuramente Votorantim (7) (na época um dos muitos vilarejos de Sorocaba) começasse a despontar tanto pela sua economia como pela sua história, uma vez que o local cedia o nome ao grupo industrial e ambos passaram a desfrutar de uma saga de prosperidade.

As empresas prosperavam, o que ocorreu com a indústria têxtil já no primeiro momento. A produção de tecido aumentou durante a década de 1920 (8), pois a concorrência internacional, principalmente a européia, operava em baixa por conta da $1^{\text {a }}$ Guerra Mundial que assolou 0 velho continente. Isso fez com que as indústrias brasileiras, de um modo geral, fossem favorecidas aumentando sua produção e vendendo para o exterior, visto que os produtos brasileiros eram de custo menor que os outros e ainda tinham um manancial de matéria-prima que não fora destruído pela guerra. Isso possibilitaria o aumento do capital do grupo já que, além das exportações, foi se consolidando a venda de tecidos no mercado interno. Já com um capital considerável, Pereira Ignácio torna-se sócio majoritário da Votorantim e adquire um velho forno de cal na região periférica, que se tornaria a cidade de Votorantim. Nessa nova empreitada durante a década de 1930, foi sendo explorado o potencial mineral do local, rico em calcário, matéria-prima base da cal e do cimento. Assim o comendador preparou a expansão e diversificação dos seus empreendimentos, construindo a fábrica de cimentos Santa Helena. Criou junto à empresa o bairro industrial de Santa Helena, que existiu até os meados da década de 1990.

A construção desse bairro ajudou na edificação desse mito, pois conforme acontecia com os moradores e operários da fábrica de tecidos, os 
trabalhadores da fábrica de cimento viam com muita benevolência o empréstimo (9) dessas casas. Isso fica demonstrado, nas muitas fotografias dos acervos pessoais dos extrabalhadores, suas lembranças mais carinhosas se referem a esse sistema de moradia feito pela Votorantim. Em 1925 José Ermírio de Moraes torna-se genro de Pereira Ignácio e, a convite de seu sogro, assume a superintendência do Grupo, onde trabalhava desde 1924. Essa união também costuma ser relacionada ao desenvolvimento da cidade, pois José Ermírio que sempre ostentou ser um filantropo, um "rotariano" (10), "investiu" no setor social, apadrinhando escolas, os então "grupos escolares", e criou os chamados parques infantis que, estrategicamente, eram construídos nas proximidades da empresa. Os dois primeiros parques infantis criados nessa época levam o nome da família Ermírio de Moraes (como Maria Helena de Moraes). Em São Paulo atuou de maneira semeIhante, pois em 1945, compra já falido, o Colégio Liceu Pedro II, mantendo todos os professores e todas as aulas. No ano posterior transfere a responsabilidade para o Rotary de São Paulo.

A década de 1960 trouxe uma grande agitação para os moradores e operários locais, já que os políticos e formadores de opinião, descontentes com a administração de Sorocaba, começaram a se reunir pregando para a população o desmembramento dessa cidade. Após uma série de manifestações públicas e da realização de um plebiscito a Assembléia Legislativa do Estado de São Paulo, em 1963 concedeu a Votorantim como desmembramento de Sorocaba. Entretanto a instalação administrativa só ocorreria em 1964 (11). É importante ressaltar que o Grupo Votorantim apoiou com recursos financeiros e ideológicos o desmembramento de Sorocaba, pois havia interesses de financeiros, já que a cidade recém criada iria reduzir a carga tributária das empresas.

Pode-se perceber que a cidade de Votorantim teve na sua consolidação uma mão influente das indústrias Votorantim. Esses fatos ocorridos na primeira metade do século $X X$ foram decisivos para construção do mito em torno da família Ermírio de Moraes, que se perpetua entre as décadas de 1970-1980, sendo utilizado e desdobrado em outras cidades e outros estados por onde a Votorantim aumentava seu patrimônio, diversificando seus empreendimentos. Até a década de 1960 as Indústrias Votorantim já tinham estabelecido negócios significativos em mais de uma dezena de cidades do Estado de São Paulo e estava presente em outros seis estados brasileiros, diferenciando-se da maioria das indústrias do país ao conseguir manter seu ritmo de crescimento, diversificar seu ramo de atuação e adentrar o novo milênio mantendo a família no comando dos negócios (12).

\section{A utilização dos arquivos na construção da história}

Nesse longo processo, que envolveu a construção de um passado comum, de uma identidade única que dá motivação ao funcionário para ser membro ativo do Grupo Votorantim, constituíram-se acervos documentais, tanto nas instituições locais quanto nas famílias de moradores, que formaram seus arquivos pessoais. Acervos que a partir de 1998, foram sendo centralizados no PMV.

Nas pesquisas realizadas percebemos a formação de conjuntos selecionados de documentos e objetos, criados especificamente para rememorar, perpetuando os feitos da família Moraes e as vivências do cotidiano de suas indústrias. Esse fato é perceptível nos menus de acesso ao site do PMV. Seja por uma busca cronológica ou por assuntos (divididos em: História do Brasil/Mundo, Negócios e Empreendedores), a figura dessa tríade aparece de forma proeminente nessas guias de acesso. Até mesmo as instituições que guardam documentação pública e que, em princípio, não cumprem funções culturais - como cartórios, órgãos públicos e setores diversos da administração das Prefeituras de Votorantim e Sorocaba - mantêm coleções de documentos que são reproduzidas no site. Muito desses conjuntos documentais são separados de suas séries documentais ou de seus fundos de origem, com a finalidade de alimentar seu caráter memorável e de valorizar seu patrimônio de informações sobre essa temática. No caso das instituições de caráter cultural, essa prática é bastante acentuada e pode ser verificada, por exemplo, em dossiês temáticos - de documentos ou de informações processadas previamente preparadas para atendimento aos usuários. Nesses dois casos foram utilizados fragmentos de arquivos para a formação do "fundo arquivístico" do PMV. O que nos traz para a reflexão de questões-chave: que critérios presidem a formação desses conjuntos documentais? A que demandas pretendem atender? O que está sendo valorizado em seus conteúdos informativos? Quais os assuntos predominantes e recorrentes? Como se dá o entrelaçamento da memória? Como os arquivos cedidos pelos trabalhadores são tratados na perspectiva global do PMV.? Que percepções se formam com sua "participação" em um engendrado site que mescla a suas histórias de vida com a história do Grupo e a história nacional (13)? 
Uma das perguntas mais importantes que preside esta pesquisa é a tênue fronteira que pode ser observada entre o espaço público e o privado, na medida em que a percepção das histórias de vida está mesclada com as versões sobre o grupo Votorantim e sobre seu papel na história local e nacional. Como isso se constrói e ganha concretude nos arquivos institucionais e pessoais?

Mesmo os trabalhos que não tiveram como objetivo direto o estudo dessas questões contribuem para o seu entendimento. Maria Celina Soares de Mello e Silva (14) estudou arquivos de cientistas brasileiros que atuam em laboratórios de pesquisa. Uma das observações mais importantes que faz é sobre a percepção que esses cientistas têm de seus documentos. Não reconhecem a sua natureza institucional, considerandoos como documentos "particulares", desconhecendo seu caráter pessoal-institucional. Como podemos aprofundar as reflexões sobre essas formas de entendimento dos registros e testemunhos das ações humanas?

Os estudos de arquivologia têm procurado desvendá-las. Terry Cook (1998) faz uma discussão séria e consistente sobre essas questões e a teoria arquivística. Também nesse sentido deve ser feita a referência ao livro recente de Camargo e Goulart (2007) sobre o arquivo de Fernando Henrique Cardoso, que também explora essas fronteiras tênues entre o pessoal e o institucional, entre o público e o privado (15).

Goulart, ao refletir sobre os modelos de gestão de arquivo, comenta como no modelo norteamericano a preservação de arquivos gerados pelas empresas privadas caminhou junto com a business history (modalidade da historiografia voltada para a história das empresas). Assim sendo, a legitimação acadêmica das histórias das empresas nos EUA veio em paralelo com a produção dos arquivos que foram gerados por elas desde 1925, incentivando estudos microeconômicos em contraponto aos dados governamentais (16). Contudo, esses estudos, por inúmeras razões, não conseguem estabelecer uma diplomática constante com o mundo dos arquivos, visto como são descritas as obras sobre esse tema, onde muitas vezes limitam-se a citar dados de revistas voltados ao mundo dos negócios, sem explorar o arquivos gerado pelas empresas. O PMV. tem como um dos seus objetivos dispor parte de sua documentação para análise acadêmica, sugerindo que ao adentrar no mundo "mágico" dos arquivos e que a cada vez que nele se aprofunda, podem-se sentir os longos galhos de uma árvore arranjada em memórias dispostas pelo projeto.
Em muitos desses estudos, é perceptível o destaque dado ao valor que os arquivos adquirem. Principalmente em poder comprovar, certificar ou validar uma história. É importante poder conhecer e desvendar o poder probatório que esses conjuntos documentais adquirem quando selecionados e expostos no site, que tipo de história se quer comprovar? Quais arquivos ficam dispostos para pesquisa acadêmica? Isso nos traz a questão do por que uma indústria do porte da Votorantim empenha um grande esforço em criar um centro de documentação que seja referência e como isso se reflete nos negócios da empresa.

Portanto, quando as instituições formam acervos específicos sobre determinados acontecimentos, temas ou personagens, qual o sentido que se pretende dar a eles? O que se deseja valorizar e a que interpretações de fatos ou processos se pretende conduzir o seu usuário? (17).

A identificação do patrimônio documental guardado pelo Instituto Votorantim e o PMV. e que também está presente nos acervos pessoais, formados pela maioria das famílias que já trabaIharam ou que ainda trabalham nas empresas do Grupo Votorantim, permitirá observar como se dá o imbricamento entre as histórias de vida dessas pessoas e a história das empresas do Grupo Votorantim, e como isso se entrelaça com as histórias fragmentadas das comunidades locais.

Do que já foi visto, nesses arquivos encontramos traços da história nacional associados à logomarca da Votorantim. Fatos que transcorrem junto à instalação do grupo na cidade Votorantim, percorrem todo o século $X X$, tendo como ápice a formação do Projeto Memória Votorantim que tem, entre suas metas para 2018: "Tornar o Centro de Memória Votorantim reconhecido como um centro de referência nacional e internacional em memória da industrialização do país" (Projecto Memória Votorantim, 2010). Utilizam-se os arquivos para buscar uma das últimas barreiras a serem quebradas pelo Grupo: a legitimação de suas ações no meio acadêmico, procedendo à organização de sua massa documental para referenciar, em pesquisas as ações de seus benevolentes patronos.

Cada um desses acontecimentos, que tiveram a participação direta ou indireta do grupo Votorantim, pode ser visto sob outra perspectiva histórica: a perspectiva de quem viveu uma história costurada junto à construção da modernidade (18) do país, onde a veneração à empresa se tornou parte dos hábitos e das lembranças da maioria dos trabalhadores locais.

Rastrear e analisar esses registros documentais são uma etapa fundamental para compreender 
a importância do Grupo Votorantim na construção da modernidade do país, as formas de sua representação no imaginário e como esse trabaIho foi sendo legitimado e propagado pelo PMV. Em sua trajetória de ascensão está o papel que desempenhou no re-enquadramento dos elos estabelecidos entre a indústria e os trabalhadores. Esse mecanismo de coesão social deve ser compreendido como um processo historicamente construído, ao longo do século XX.

\section{Considerações teóricas}

A riqueza da história do Grupo Votorantim é sustentada pelos estudos, tanto de cunho acadêmico quanto de natureza memorialística, que se apóiam no detalhamento da produção arquivística guardada ao longo de quase um século, a princípio pelos próprios operários e, a posteriori (19), reunida pelas intuições públicas e privadas, em especial pelo PMV. A pesquisa pode permitir levantar hipóteses sobre as motivações e intenções que levaram à reunião desses arquivos. Não obstante, são muitas as possibilidades que a teoria arquivista, gera para compor uma análise aprofundada desses assuntos. Ao tentar compreender a finalidade da Formação do PMV. e de seus conjuntos documentais, é possível utilizar um variado leque teórico, incluindo autores da Arquivística, da Sociologia, Psicologia, História entre outros.

Na pesquisa de iniciação científica foi feita uma análise dos estudos históricos e das biografias produzidas, respectivamente sobre a cidade, o Grupo e os empresários. A intenção foi identificar os arquivos e os documentos que foram utilizados nessas obras.

O mesmo vem sendo feito agora, na pósgraduação, para os conjuntos documentais disponibilizados no site, visando transmitir aos leitores a construção de uma memória comum. Desde já, há perguntas a fazer: e os arquivos que ficaram de fora? Qual o lugar de "o não dito"? "O que fica por detrás da história"? O que mostraram e o que não mostraram os arquivos nessa tentativa de construção comum? Michel de Foucault (21) e Certeau (22) atribuíram grande importância para o que está por trás da construção da história, ainda seguindo essa linha de raciocínio podemos indagar a permanência dos arquivos na página do PMV., quais critérios levaram a composição das exposições virtuais temáticas e sua permanência on line.

Silvana Goulart (2005), recorrendo a Le Goff, nos mostra como os arquivos institucionais privados são importantes, pois são as únicas fontes que mostram a vida cotidiana da empresa e dos homens, e complementa:
A memória reunida pelas instituições é matéria para construção de sua história que, uma vez pesquisada e escrita, pode ser editada em diversos formatos (...) a história de organização cria valor e ajuda a defender a sua imagem para públicos estratégicos.

É evidente a importância do PMV. e de seu site, pois eles focam exatamente a construção da história do Grupo Votorantim e, para isso, recoIhem material dentre os ex e os atuais funcionários para elaborar e disseminar essa história dentro e fora da empresa. É importante prestar atenção ao modo como o site foi estruturado. Conforme sugerem as abordagens teóricas da História e da Arquivologia, é possível perceber as relações que seus construtores pretendem estabelecer entre o público que o acessa e a memória local e institucional construída a partir dos seus documentos e da disposição das informações (Jardim, 1999).

Silvana Goulart, juntamente com Ana Maria Camargo (2007), na obra "Tempo e Circunstância", chama a atenção para o modo como a produção dos arquivos institucionais coincide com as atividades e funções do organismo e assume caráter de rotina cujo cumprimento, obediente às normas e tradições, está previsto no âmbito de suas competências e encargos. Essa pertinência levantada pelas autoras se verifica na formação do acervo do PMV. já que o fluxograma dos arquivos segue a hierarquia observada no organograma de negócios da Votorantim e, assim, é escamoteado na constituição da memória. Ademais, Camargo e Goulart sinalizam as tênues fronteiras que demarcam os acervos pessoais e sugerem que a instituição empresarial assimila os arquivos pessoais de seus empresários e de seus proprietários para estabelecer um elo coeso de uma memória comum.

Goulart, na obra "Patrimônio documental e história institucional", trabalha especificamente sobre a massa documental acumulada pelas empresas ao longo dos anos, analisando o modo como as instituições particulares e em especial das indústrias foram construindo centros de documentação, no intuito de preservar sua memória, de construir e/ou reforçar um elo de identidade com seus empregados ou por questões de marketing e estratégia, reforçando e por vezes reformulando sua imagem para os clientes. Nessa obra Goulart faz importantes apontamentos de como nasceram os primeiros centros de memória institucionais das indústrias no país e os objetivos porque foram criados. A motivação de reunir seus arquivos (muitas vezes fragmentados), para que não se perdesse o passado da empresas, principalmente quando 
acontecessem aquisições e fusões, ocasionando na mudança das marcas e nomes de seus produtos. Outro apontamento importante feito por Goulart diz respeito justamente aos processos de criação de centros de memória nas cidades do interior. Ao tentar criar a história das empresas acaba-se criando a história das cidades, onde a memória e os arquivos de ambos estão imbricados, por vezes fundidos.

Nessa linha, outro trabalho importante sobre essa temática é o artigo: "Centros de documentação e pesquisa histórica: uma trajetória de três décadas" de autoria de Célia Reis Camargo. Como sugere o tema, a autora analisa entre os anos de 1970 - 2000, a criação dos centros de memória no país, apontando o quadro que explica como essas instituições, principalmente as de caráter público, foram criadas, frente ao descaso pela informação contida nos arquivos brasileiros. $\mathrm{E}$ como, com o surgimento desses órgãos de guarda, as fontes documentais passaram a ter um acesso mais amplo e principalmente porque muitos desses centros foram criados ou então ganharam a perspectiva ligada à pesquisa. Reis Camargo também observa durante essas três décadas como esses centros foram passando por modificações. O Centro de Pesquisa e Documentação (CPDOC) (22), que foi pioneiro em desenvolver políticas e metodologia, tornou-se modelo de referência para esses centros. Assim é pertinente investigar se houve do PMV. uma intenção de busca dos fundamentos teóricos e concepções de outros centros de documentação e memória já implantados.

Como o projeto trata de um conjunto documental que foi digitalizado e disponibilizado na internet, a obra "Arquivística temas contemporâneos" traz importantes reflexões, principalmente o artigo de Humberto Innarelli, que apresenta os mandamentos da preservação digital. Essa construção preventiva descrita pelo autor dá fundamento para analisar como foi digitalizada a documentação e disponibilizada na construção do site, uma vez que Innarelli sinaliza a importância e confiabilidade dos meios de suportes digitais, hardwares, softwares, sistemas gerenciadores. Com essas ferramentas teóricas podese aferir se houve e qual foi o método elaborado para a digitalização e a disponibilização desses arquivos. Já os outros dois artigos, de Vanderlei dos Santos e Renato de Souza, serão alusivos a desvendar como o PMV. trabalhou o conceito de informação, qual instrumental teórico foi utilizado para a construção do projeto e quais processos foram adotados. É importante destacar também a preocupação desses profissionais descrita nas páginas de seus artigos: uma vez que metas são atingidas, o que se faz com a informação guardada e todo seu procedimento? A meta maior do PMV. deve ser alcançada em 2018. Depois desse período, quais são os planos para todos os arquivos que foram reunidos e apresentados pela Votorantim? Quais são as estratégias a longo prazo para preservação dessa empreitada informacional?

Ainda nesse ínterim, a obra "Gestão de Documentos Eletrônicos - uma visão arquivística”, de Vanderlei Batista dos Santos, se faz importante para analisar como se é preservado a documentação disponível da interface do site, bem como esse livro contem um estudo comentado das legislações referentes a informação e documentação digital. Pertinente a pesquisa, uma vez que a empresa disponibiliza a fotografia de cada um de seus funcionários e os depoimentos orais de seu acervo através do site, como parte da imagem do Grupo. Como essa questão se relaciona de forma ética, com a fusão da imagem pessoal com a imagem institucional?

Os artigos que compõem o livro "Arquivos, Patrimônio e Memória. Trajetórias e Perspectivas", organizado por Zélia Lopes são frutos de reflexos e práticas de trabalhos com arquivos, centro de documentações e centros de memória. A segunda parte do livro enfoca como as instituições arquivísticas tratam e disponibilizam seus acervos, assim foram destacados os capítulos que tratavam da organização de acervos, arquivos e coleções fotográficas, para comparar em compreender como se compões a arquitetura do PMV.

Já nesse foco, adentrando na problemática de como foi produzida, organizada e disponibilizada a informação do PMV., foi-me necessário ter embasamento teórico criterioso para descobrir se as questões da elaboração dos fundos, como ele foi organizado na sua forma material e disposto no centro de documentação do Projeto, como as fotografias foram catalogadas, restauradas e tratadas e se seguiram as recomendações normativas da arquivística; foram utilizadas as seguintes obras: "Como Classificar e Ordenar Documentos de Arquivos" de Janice Gonçalves, e "Como Tratar Coleções de Fotografias" de Patrícia de Fellipi, Solange Ferraz de Lima e Vânia Carneiro de Carvalho. Nesse ínterim é importante para essa pesquisa a obra "Arquivos Permanentes: Tratamento Documental" de Heloisa Bellotto traz importantes subsídios para compreender e dialogar com o que o PMV. entende por arquivos e o tratamento dado por eles. E isso se torna tão peculiar uma vez que são escassas as referências bibliográficas sobre arquivologia tanto quanto ao projeto memória, quanto a concepção do acervo geral do Instituto Votorantim, e que ele compreende pela 
"identificação do fundo" a "sistemática do arranjo". Entre outros. Colocaria mais autores ligados à Arquivologia como Bellotto, etc., no entendimento da organização arquivística e no recorte que fizeram na documentação.

Sobre a possibilidade de recorrer parcialmente à História Oral, na execução desta pesquisa, a leitura do livro "A voz do passado" de Paul Thompson é a referência maior, ao lado do trabaIho de Ecléa Bosi, "História e Sociedade: Lembrança de Velho". Considerado o organizador da História Oral Contemporânea, Thompson oferece vários conceitos, metodologias e formas de abordagem baseados nas suas diversas experiências com relatos orais. Thompson reconhece o valor que as fontes orais constituem e como elas podem ser relevantes para informar sobre as dimensões da história que não podem ser preenchidas por outras fontes documentais. Esse autor se torna ainda mais importante para essa pesquisa, pois ele é uma das referencias teóricas utilizadas na construção do PMV. De acordo com suas informações, seus conceitos fundamentaram a reunião do acervo, a concepção do site e, principalmente, as formas de coleta dos relatos orais dos funcionários da empresa.

Esse estudo procura entender como se deu a formação do "Projeto Memória Votorantim", como ele deu suporte à narrativa mítica da família Ermírio de Moraes e como isso consolidou uma identidade corporativa entre a empresa e seus trabalhadores, usando como base fundamental a documentação arquivística disponível.

Trata-se de uma pesquisa que procura discutir como o processo de formação do acervo do projeto memória favoreceu uma seleção de arquivos que podem confirmar a construção de um mito em torno dos proprietários do Grupo Votorantim e como, de maneira meticulosa, ela foi saindo de uma esfera da construção da memória local da cidade de Votorantim e alcançou o patamar do nacional.

Seus objetivos fundamentais são: a) Compreender o papel e a função dos arquivos no processo de construção da memória comum entre a empresa e seus trabalhadores; b) Contribuir para o estudo da relação entre arquivos e construções biográficas e corporativas de várias modalidades; c) Identificar e descrever as tipologias documentais encontradas no acervo do PMV.

\section{Entendimentos de como se compõe uma memória corporativa}

Como já se fez referência neste artigo, a produção científica recente, particularmente aquela que trata dos arquivos institucionais, vem abordando os arquivos de forma a construir um consenso quanto à idéia de que os tipos de documentos acumulados e guardados, as formas como seus titulares organizam seus documentos, os critérios de guarda de uns e de eliminação de outros, os objetos e os documentos bibliográficos a ele relacionados (colecionados e também guardados), enfim, o conjunto documental construído pode expressar uma intenção autobiográfica, uma imagem que as pessoas formulam de si mesmas ou que produzem para os outros.

Os entendimentos sobre a composição da memória, como se estrutura uma memória coletiva, são até hoje objetos de estudos e muitos são orientados com primazia por Halbawachs (1990). Nesse estudo o autor destaca como se perpetua uma memória coletiva de acordo com as necessidades ou finalidades de grupos. Entender como se dá e qual as motivações para construir, ou melhor, compor uma memória, é uma tarefa que exige muita observação. Há vários fatores que influem na composição de uma memória e sedimentá-la é uma tarefa igualmente difícil, pois envolvem as naturezas materiais e imateriais, que são portadoras de um simbolismo especifico a este grupo.

A memória é subjetiva e é inerente ao que cada pessoa observa e guarda das suas ações ou do grupo. Assim compor uma memória corporativa comum que seja referenciada por todos dentro da empresa, agregará fatores imateriais como sedimentação de uma identidade comum, eventos marcantes, imposição de valores, estabelecer uma relação hierárquica com base familiar, são alguns desses exemplos. Na soma desses elementos, os fatores materiais como, fotografias, textos, objetos, pinturas, aumentam a valoração da memória ao mesmo ponto que são utilizados para validar as ações institucionais da empresa. Como Halbawachs aponta: "cada objeto encontrado, e o lugar que ocupa no conjunto, lembramnos uma maneira de ser comum a muitos homens." Esses objetos muitas vezes são distribuídos aos funcionários da empresa, com a intenção de realçar os fatores imateriais e constituir uma identidade e uma memória comum.

As ações institucionais para compor uma memória corporativa, são apontadas por Goulart (2005) como parte de uma estratégia que pode ser utilizada pelas empresas com fins de negócios e ou sociais. Sendo assim a criação de centros de memória, com a finalidade de preservar os feitos e memória da empresa, torna-se uma pratica de negócios. Dessa maneira muitas empresas criaram centros de documentação ou centros de memória no Brasil, de inicio para 
preservar seu passado e a natureza de seus negócios, posteriormente como uma ação de marketing, pois isso agrega valores sociais às corporações e as tornam mais amistosas aos clientes.

Dessa forma, a memória corporativa não será a memória de cada trabalhador, ela se fundamentará nesse grupo para estabelecer uma memória comum. Esse núcleo comum da memória corporativa, em especifico da Votorantim, girará em torno de seus Patriarcas. Toda lembrança ou narrativa dos funcionários será laureada, por fotos, documentos, cartas, e objetos que tiveram uma ligação especial com a empresa, ou por eventos organizados e ou patrocinados por ela, durante todos os anos de atividade da empresa. Posteriormente, reunir todo o patrimônio documental, seja ele de origem da instituição e principalmente o que está em posse dos trabalhadores, e depositá-lo em um único lugar para estudo ou consulta, dará concretude a composição da memória corporativa. Pois guardamos somente aquilo que nos traz um real valor e um grande significado. Como bem apontou Artières (1998).

arquivamos nossas vidas para responder a uma injunção social (...) Mas não arquivamos nossas vidas, não pomos nossas vidas em conserva de qualquer maneira, (...) fazemos um acordo com a realidade, manipulamos a existência: omitimos, rasuramos, riscamos, sublinhamos, damos destaque a certas passagens.

Por isso para efeitos da pesquisa, esse entendimento dos arquivos institucionais corporativos, também pode ser estendido aos arquivos pessoais e aos de entidades e órgãos voltados para a preservação do patrimônio histórico e cultural (arquivos que contribuíram para origem do fundo PMV.). Uma reflexão importante feita por Reis Camargo, no que diz respeito à relação dos arquivos pessoais com as instituições que o adquirem: muitas vezes a falta de procedimentos técnicos adequados dessas instituições acarreta na fragmentação dos arquivos, transformando seu acervo em uma "colcha de retaIhos", pois selecionam, tratam e disponibilizam somente aquilo que os interessa, sem ter um projeto global de composição de informação para o desenvolvimento de uma área de conhecimento (Camargo, 2003).

\section{Um centro de memória concebido para web?}

O Projeto Memória Votorantim é organizado pelo Grupo Votorantim, a cargo do Museu da Pessoa. Seu acervo fica localizado no escritório central da Votorantim, na Praça Ramos de Aze- vedo, no antigo Hotel Esplanada, na cidade de São Paulo (SP). A iniciativa do projeto, conforme o próprio site, é "a implantação do Centro de Memória Votorantim através de ações de resgate e preservação da história do Grupo. A construção desse programa consistente de memória institucional envolve a história dos funcionários e das comunidades nas quais a empresa está inserida. Ao mesmo tempo, promove um programa de pesquisa permanente, que inclui ações de preservação do patrimônio arquivístico e museológico".

O acervo da Votorantim é imenso, integrado por mais de 80 mil documentos, entre cartas, textos, relatórios, fotografias, depoimentos, vídeos, jornais. Todos organizados e catalogados por tipologia. No site, o modo de consulta principal pode ser feito da seguinte maneira: datas (separadas em espaço de décadas); pessoas (onde constam depoimentos e fotografias em ordem alfabética); história do grupo (separado por décadas onde aparecem novos links que, quando selecionados, mostram a linha do tempo da década; de acordo com o ano podem aparecer fotos, vídeos ou documentos); linha do tempo (onde se subdivide em data ou assunto, subdivido em Mundo/Brasil, Negócios e Empreendedores); Multimídia (onde aparecem os links fotos, vídeos e documentos que vão ser subdivididos, por período ou por assunto - esse oferece 48 descritores); Exposições (são seis exposições; duas que retratam a história do país e as outras quatro sobre a Votorantim; cada exposição contém fotos e textos). É possível ao consulente executar a pesquisa do modo que mais se adequar aos seus objetivos.

O Projeto Memória Votorantim estruturou seus arquivos com o objetivo de contar a história do Grupo Votorantim, dando ênfase nessa empresa no cenário nacional e isso pode ser verificado pela cronologia factual que foi montada, onde entre os fatos da História do Brasil e do Mundo está a história da empresa. Essa documentação foi constituída, em parte, pela da massa documental (fotografia e textual) gerada pela empresa ao longo de sua existência, sendo que alguns desses conjuntos documentais foram recuperados ou restaurados. Conforme informação do próprio site pode-se encontrar a fotografia de todos os funcionários da Votorantim e indicações de onde eles trabalham atualmente.

A outra parte da documentação foi formada pelos próprios funcionários ou colaboradores externos que cederam ou permitiram a reprodução digital de suas fotos ou documentos. E isso é muito interessante, pois muitas fotos das primeiras décadas da empresa foram adquiridas das unidades e ou advindas de seus emprega- 
dos. Esse projeto que tem metas estabelecidas até 2018, ano do centenário da empresa, tem como perspectiva além de gerar produtos institucionais, o intuito de fortalecimento da identidade do trabalhador com a Votorantim e em suas páginas se transcende o conceito de história individual do "eu" trabalhador para a história do "nós' empresa. Isso pode ser verificado na ordem sugerida pelo Guia do Acervo, onde o primeiro conjunto descrito é o da "Memória Corporativa", seguindo-se o de "Memória de tecidos", a "Memória dos Funcionários", e a divisão continua com "Memória Cimentos," "Memória Metais", "Memória Alumínio", "Memória Nitro Química", "Memória Celulose e Papel” e "Memória Energia"; segundo o próprio quadro estrutural do acervo cada "Memória" corresponde a um unidade de Negócios.

Cada uma dessas "Memórias" é composta, dividida e catalogada, contemplando os documentos textuais (de acordo com a tipologia) e os documentos Iconográficos (por conjuntos ou coleções). Além das fotografais e documentos textuais o acervo físico é composto de filmes super 8, DVDs, manuscritos, mapas, livros, revistas, medalhas, pequenos objetos datados desde 1894, agrupados por área de atuação da empresa.

O acervo virtual pode ser consultado $24 \mathrm{~h}$ por dia no site www.memoriavotorantim.com.br. Já o acervo físico pode ser consultado mediante agendamento com os responsáveis pelo projeto. Pretendo, em minha pesquisa, fazer uma coleta de dados in loco, principalmente com o objetivo de rastrear o histórico dos documentos cedidos ou reproduzidos e como foram escolhidos para compor o fundo, e entender o critério da instituição no que tange à disponibilização dos documentos on line.

A grande questão da problemática apresentada por essa pesquisa ainda permanece vaga na tentativa de responder as questões éticas, da formação desse controle de memória. Será ético instituir um centro de memória, tendo como base arquivos pessoais de funcionários (ex- e atuais), que foram dados pelas empresas aos longos dos anos, guardados carinhosamente como troféus valiosos. E de que forma essa "memória espalhada" foi reagrupada, reconstituída e re-configurada para criar o PMV., sem muitas vezes referenciar os donos dos documentos? O mesmo vale para as Instituições Públicas e Privadas que tiveram partes de seus conjuntos documentais reproduzidos nesse projeto memória? Mesmo que no caso das instituições a referência fora devidamente feita, se fragmenta a reprodução do conjunto documental original para agrupar e criar outro. Nesse caso quais questões éticas estão sendo deixadas de lado? Como se aplicaria a ética na explicação de constituir uma interface digital onde a memória do trabalhador é ferramenta constitutiva para fundamentar e formar a memória institucional e corporativa. Essas indagações merecem não só um estudo mais aprofundado como uma atenção maior da sociedade.

Até o momento, estamos arrolando os tipos documentais que os funcionários disponibilizaram para compor essa memória, analisando se esses documentos são apropriados para compor uma memória corporativa, considerando-se valores administrativos, probatórios e relevância no cotidiano da empresa. Esse levantamento aponta várias direções a serem estudas e consideradas, já que ao mesmo tempo há uma crítica sobre a utilização da memória como peça de estratégia de negócios, em contraposição a uma corrente que não só aceita como justifica a exposição dessa memória on line, mesmo que o trabalhador não tenha conhecimento dessa estratégia, mas aceita participar, pois se reconhece como parte de uma história maior e se enxerga na identidade da empresa. Dessa forma, acreditamos que ao identificarmos os documentos que foram disponibilizados on line, conseguiremos estabelecer os padrões que a corporação adotou na formação de sua memória empresarial e discutir a validade e intencionalidade desses critérios.

\section{Notas}

(1) PMV. faz parte de uma das ações sociais do Instituto Votorantim, braço filantrópico do Grupo Votorantim Maior Conglomerado Empresarial e Industrial familiar do Brasil, que com quase um século de existência diversificou sua produção que vai de suco de laranja a produção de cimento e metais. E resiste firmemente a Globalização e ao investimento do capital estrangeiro. Pois desde 1917 até a presente data, $85 \%$ do Grupo é controlado pelo Conselho de Família Ermírio de Moraes. Esse estudo é fruto dos meus trabalhos de Iniciação Científica da graduação, que foi financiada pela Fundação de Apoio a Pesquisa do Estado de São Paulo - FAPESP, sobe a orientação da Doutora Célia Reis Camargo Professora do Departamento de História da UNESP Assis - e de Pós-Graduação em Ciência da Informação sob a orientação da Doutora Telma Campanha de Carvalho Madio - Professora do Departamento de Ciência da Informação da UNESP Marília.

(2) Termo utilizado originalmente no artigo de Luisi Passerini (1993).

(3) Conforme foi apontado no meu relatório de Iniciação Científica: "Votorantim: uma cascata de lembranças - os arquivos locais na construção da memória coletiva (1917 - 2007)."

(4) Local do antigo Hotel Esplanada, que desde 1965 é utilizado como escritório-sede da Votorantim, no centro financeiro da época na cidade de São Paulo

(5) As características físicas, geológicas e geográficas de Sorocaba e de Votorantim, bem como a herança de seu 
passado colonial, foram explanadas no Relatório Cientifico: "Votorantim: uma cascata de lembranças. Os arquivos locais na construção da memória coletiva (1917 2007)", apresentado à FAPESP em janeiro de 2009.

(6) O Comendador adquiriu a massa falida do Banco União junto a outros sócios entre eles o Conde Scarpa e, posteriormente tornou-se único dono das empresas, cf.: SCANTIMBURGO, João de. José Ermírio de Moraes, o homem - a obra. São Paulo: Companhia Editora Nacional, 1975.

(7) O nome "Votorantim" origina do tupi-guarani e significa "cascata branca", devido às várias quedas d'água existente no local. Que já foram motivos de visita do Imperador D. Pedro II e objeto de descrição de Saint-Hilaire, na sua viagem a província de São Paulo.

(8) A Fábrica de tecidos da Votorantim era uma das maiores empregadoras do Estado de São Paulo, com aproximadamente 3.400 empregos diretos. (memoriavotorantim.com.br, 2008).

(9) As casas estavam condicionadas ao emprego nas indústrias. Isso deixava os operários amarrados a uma ideologia trabalhista familiar. Pois já que constituíam família, que dependia da casa, os operários acabavam aceitando, compassivamente e com uma percepção benevolente o sistema de trabalho que lhes era imposto.

(10) Scantimburgo (1975) enfatiza o perfil filantropo de J.E.M. Menciona sua participação com membro do Rotary e, sua atuação social, dando manutenção a grupos escolares e colégios, criando creches e hospitais para os funcionários de suas empresas.

(11) Segundo João dos Santos Jr. (2004), após longa campanha, onde aconteceram debates e um plebiscito a Assembléia Legislativa de São Paulo votou e consentiu no desmembramento. Essa audiência foi assistida por centenas de pessoas que organizaram uma caravana com carros e ônibus para acompanhar a votação. Entretanto, com o golpe, a instalação do município só aconteceu em dezembro de 1964, após algumas medidas dos militares de âmbito nacional.

(12) No organograma administrativo das Indústrias Votorantim os membros da família desempenham papel deliberativo em dois Conselhos: o Administrativo e o Conselho de Família, mostrando a força que mantém essa corporação ainda familiar.

(13) No site do projeto é possível encontrar além de documentação escrita e iconográfica, transcrições de entrevistas e depoimentos orais. Outro ponto audacioso do projeto é que ele possui a fotografia de todas as pessoas que trabalham no Grupo Votorantim em suas mais variadas empresas.

(14) Visitando laboratórios: o cientista e a preservação de documentos.

(15) Sobre aspectos conceituais dessa questão não se pode deixar de utilizar, com suporte teórico, o trabalho de Habermas (2003).

(16) Isso ocorreu com a criação da Business History Society junto a Universidade de Havard, como é mencionado em Goulart (2005).

(17) Muito esclarecedor sobre esses aspectos da questão é o trabalho de David Olson (1997). Numa outra linha de reflexão está A lógica da escrita e a organização da sociedade, de Jack Goody.

(18) Fernando Henrique Cardoso dedicou sua Livre Docência à questão da industrialização e da modernidade do país, entrevistando empresários e industriais da década 70 resultando na obra de Cardoso (1971).
(19) A memória como espaço disputa, principalmente no que se refere a uma memória imposta à classe operária foi trabalhada por Edgar De Decca (1981)como uma dissolução da memória histórica. A revolução do vencedor que se apropriou da memória dos trabalhadores e escreveu uma história dos vencedores. 1930 O Silêncio dos Vencidos: memória, história e revolução. 1981.

(20) Foucault (1987) também faz considerações importantes sobre como analisar o que foi escrito em um discurso histórico, como ele se formou e porque foi escrito. Ele aponta essas considerações quanto à estruturação de um arquivo.

(21) Certeau (1982), faz importantes considerações ao analisar a forma como a História é escrita e a utilização das fontes. Aponta que o que "não é dito" nas obras é tão importante quanto o que elas retratam e, portanto, merecem uma análise. Sugere o estudo do porque tais fontes são abordadas e os critérios de escolha.

(22) O CPDOC é um dos mais conceituados e referenciados Centro de Pesquisa e Documentação do Brasil, faz parte da Fundação Getúlio Vargas e está situado na cidade do Rio de Janeiro

\section{Referencias}

Almeida, Aluísio de. Sorocaba Três Séculos de História. Itu: Ottoni, 2002

Artières Philippe. Arquivar a Própria Vida (1998). // Centro de Pesquisa e Documentação de História Contemporânea do Brasil - CPDOC. Estudos Históricos, Rio de Janeiro, 11:21 (1998).

Bellotto, Heloisa L. (2004). Arquivos Permanentes: tratamento documental. Rio de Janeiro: FGV, 2004.

Bellotto, Heloísa Liberalli; Camargo, Ana Maria de Almeida (coord.) (1996). Dicionário de Terminologia Arquivística. São Paulo: AAB-SP, Secretaria de Estado da Cultura, 1996.

Bosi, Ecléa (1987). Memória e Sociedade: lembranças de velhos. São Paulo: Edusp, 1987.

Camargo, Ana Maria de Almeida (1998). Contribuição para uma abordagem diplomática dos arquivos pessoais. // Estudos Históricos, Rio de Janeiro. 11:21 (1998) 169174.

Camargo, Ana Maria de Almeida; Goulart, Silvana (2007). Tempo e circunstância: a abordagem contextual dos arquivos pessoais. Procedimentos metodológicos adotados na organização dos documentos de Fernando Henrique Cardoso. Edição bilíngüe: português - inglês. São Paulo: Instituto Fernando Henrique Cardoso, 2007.

Camargo, C. R. À. (1999). Margem do patrimônio cultural. Estudo sobre a rede institucional de preservação do patrimônio histórico no Brasil (1838-1980). Assis, UNESP, 1999. (Doutorado em História).

Camargo, C. R. À. Os centros de documentação e pesquisa histórica: uma trajetória em três décadas anos. // CPDOC 30 anos. RJ, FGV, 2003.

Certeau. Michel de. (1982). A Escrita da História. Rio de Janeiro: Forense Universitária, 1982.

Cook, Terry (1998). Arquivos pessoais e arquivos institucionais: para um entendimento arquivístico comum da formação da memória em um mundo pós-moderno. // Estudos Históricos, Rio de Janeiro, 11:21 (1998) 129-150.

Dean Warren, A industrialização em São Paulo. São Paulo: Difel, 1971.

Departamento Do Patrimônio Histórico/ Secretaria Municipal de Cultural/ Prefeitura Municipal de São Paulo. O direito à memória. Patrimônio histórico e cidadania. SP, DPH, 1992. 
Foucault, Michel (1987). A arqueologia do saber. Rio de Janeiro: Forense Universitária, 1987.

Gonçalves, Janice (1998). Como Classificar e Ordenar documentos de arquivos. São Paulo: Arquivo do Estado, 1998.

Goulart, Silvana (2005). Patrimônio documental e história institucional. São Paulo: Associação de Arquivistas do Estado da São Paulo, 2005.

Habermas, Jugen (2003). Mudança estrutural da esfera pública. Ed. Tempo Brasileiro, 2003.

Halbachws, Maurice (1990). A Memória Coletiva. São Paulo, Vértice, 1990.

Innarelli, Humberto Celeste, Santos, Vanderlei Batista dos Santos (Org.); Sousa, Renato Tarciso Barbosa de. (2007). Arquivística: temas contemporâneos: classificação, preservação digital, gestão do conhecimento. Brasília-DF: SENAC, 2007.

Jardim, José Maria (1999). Transparência e opacidade do Estado no Brasil. Niterói, UFF, 1999.

Le Goff, Jacques (2000). História e Memória. São Paulo: Edições 70, 2000.

Martins, Kleber de Araújo (Org..) (2000). Votorantin 2000 Memórias de uma Cidade. São Paulo: Cooperativa Técnico-Educacional, 2000.

Nora, Pierre (1993). Entre Memória e História: a problemática dos lugares. // Projeto História. São Paulo: Revista do Programa de Pós-Graduação em História, dezembro de 1993.

Olson, David (1997). O mundo no papel: as implicações conceituais e cognitivas da leitura e da escrita. São Paulo: Ática, 1997.

Passerini, Luiza (1993). Mitobiografia em História Oral. Em: Projeto História. São Paulo: Revista do Programa de Pós-Graduação em História, dezembro de 1993.

Pomian, Krzysztof. Coleção (1984). // Enciclopédia Einaudi. Porto: Imprensa Nacional: Casa da Moeda, 1984.

Projecto Memória Votoratim www.memoriavotorantim.com.br (2008-12)

(2010).
Rago. Maria Aparecida de Paula. José Ermírio de Moraes a Trajetória de um empresário nacional. São Paulo: Paz \& Terra, 2008.

Rousseau, Jean-Yves e Couture, Carol. Os fundamentos da disciplina arquivística. Lisboa, Publicações Dom Quixote, 1998.

Santos Junior, João dos (2004). Votorantim: história e iconografia de uma cidade. Itu: Ottoni, 2004.

Scantimburgo, João de (1974). Menino imigrante. São Paulo: Grupo Votorantim, 1974

Scantimburgo, João de (1995). José Ermírio de Moraes, o homem - a obra. São Paulo: Companhia Editora Nacional, 1975.

Scantimburgo, João de. José Ermírio de Moraes, o homem - a obra. São Paulo: Companhia Editora Nacional, 1975.

Silva, Maria Celina Soares de Mello. Visitando Laboratórios: o cientista e a preservação de documentos. São Paulo: USP/FFLCH - Programa de Pós-graduação em História Social. Tese de doutoramento.

Silva, Zélia Lopes da (1999). Arquivos, Patrimônio e Memória Trajetórias e Perspectivas. São Paulo: UNESP 1999.

Thompson, Paul (1992). A voz do passado: história oral. Rio de Janeiro: Paz e Terra, 1992.

Vainfas, Ronaldo. Dicionário do Brasil Colonial (1500-1808), p. 565

Votorantim, Grupo (1993). Grupo Votorantim 75 anos de História 1918-1993. Votorantim, 1993.

Votorantim, Grupo (1998). Grupo Votorantim 80 anos de História 1918-1998. Votorantim, 1998.

Votorantim, Grupo (2003). Grupo Votorantim 85 anos de História 1918-2003 (dois volumes). Votorantim, 2003.

Votorantim, Grupo (2008). Grupo Votorantim 90 anos: Uma história de trabalho e superação. Votorantim, 2008.

Recibido: 18-04-2010. Revisado: 02-07-2010.

Aceptado: 06-07-2010. 